\title{
Inhalt nach Abteilungen
}

\section{Verzeichnisse}

Inhalt nach Abteilungen $\ldots \ldots \ldots \ldots \ldots \ldots \ldots \ldots \ldots, \mathrm{V}$

Inhalt nach Sachgebieten $\ldots \ldots \ldots \ldots \ldots \ldots \ldots \ldots$ VII

Abkürzungen und Siglen $\ldots \ldots \ldots \ldots \ldots \ldots \ldots \ldots$ IX

\section{Vorwort}

Uwe Carstens............................ XIII

I. Monographien $\ldots \ldots \ldots \ldots \ldots \ldots \ldots \ldots \ldots \ldots \ldots \ldots \ldots \ldots \ldots$

Politik und Moral. Eine Betrachtung ............. 3

Vereins- und Versammlungsrecht wider die

Koalitions-Freiheit ...................... 49

L'Évolution sociale en Allemagne (1890-1900) ....... 101

Die Ostseehäfen Flensburg, Kiel, Lübeck ............ 149

II. Schriften . ................................ 257

[Schreiben an die Herren Geistlichen mit der Bitte um Charakterisierung ihrer Konfirmanden] ......... 259

Mitteilungen Moralstatistik betreffend ........... 263

Auszug aus dem Begleitschreiben vom Februar 1900 .... . 269

P.P. .................................. 274

Die Erweiterung der Zwangserziehung ............ 277

Die Wohnungsnot - eine sittliche Not ............ 309

Sittliche Entrüstung? .................... 322

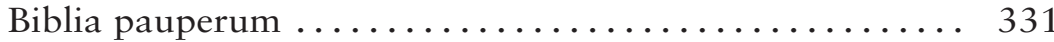

Die Verhütung des Verbrechens ................ 337

Zur Kontroverse über Politik und Moral ............ 350

Die Zerrüttung der liberalen Partei in England ........ 356

An den Präsidenten Paul Krüger ut Transvaal ......... 360

Eine Anmerkung über Rousseau ................. 362

Otto Kallsen .......................... 366

Die Krisis des englischen Staatswesens .......... 375

Zwei Briefe Klaus Groths ................... 396 
Die schöpferische Synthese.

Ein philosophisches Résumé ................. 403

Terminologische Anstösse ................... 415

Zur Theorie der Geschichte (Exkurs) ............ 424

Wilhelm Förster (Zum siebzigsten Geburtstage) ....... 456

Ammons Gesellschaftstheorie ................. 462

III. Rezension ........................... 487

Der europäische Bund .................. 489

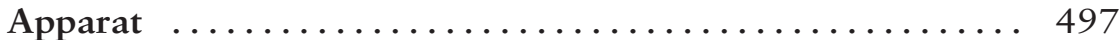

Editorischer Bericht ........................ 499

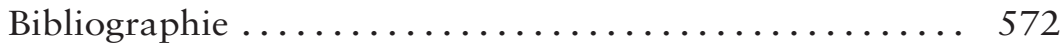

Register der Publikationsorgane ............... 599

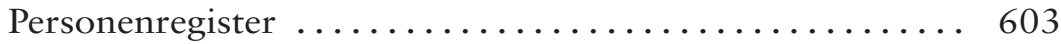

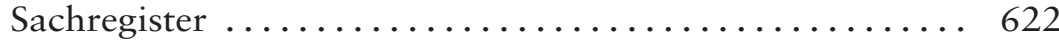

Plan der Tönnies-Gesamtausgabe ............. 637 